\title{
Holmium laser ablation of the prostate (HoLAP) with moses technology for the surgical treatment of benign prostatic hyperplasia
}

\author{
Antonio Andrea Grosso ${ }^{1}$, Fabrizio Di Maida ${ }^{1}$, Andrea Mari ${ }^{1}$, Samuele Nardoni ${ }^{1}$, Agostino Tuccio ${ }^{1}$, \\ Andrea Minervini ${ }^{1}$ \\ ${ }^{1}$ Department of Experimental and Clinical Medicine, University of Florence, Unit of Oncologic Mini- \\ mally-Invasive Urology and Andrology, Careggi Hospital, Florence, Italy
}

\section{ABSTRACT}

Purpose: The expansion of technology is leading to a paradigm shift in several urological fields $(1,2)$. In particular, the adoption of lasers within the surgical treatment of patients with benign prostatic hyperplasia (BPH) is considered one of the most relevant innovations (3-5). In this video, we aimed to report our experience with holmium laser for the ablation of the prostate (HoLAP) in patients with obstructive lower urinary tract symptoms (LUTS) due to BPH.

Materials and Methods: From 2018 to 2020, 10 patients with obstructive LUTS secondary to BPH were treated at our Institution with HoLAP (120W Holmium laser Lumenis ${ }^{\circledR}$ with Moses ${ }^{\circledR}$ technology). Main inclusion criteria were: 1) International Prostate Symptom Score $\geq 12$; 2) prostate volume $\leq 65 \mathrm{~mL}$, 3) maximal flow rate (Qmax) $\leq 15 \mathrm{ml} / \mathrm{s}$ at preoperative non-invasive uroflowmetry.

Results: Mean patient age was 65 (range: 59-72) years. Preoperative mean prostate volume was 50 (range: 35-65) mL. Mean operative time was 66 (range: 45-85) minutes with a mean laser time/operative time ratio of 0.51 (range: 0.440.60). Voiding symptoms, Qmax and post voiding residual were significantly improved after 3 and 12 months (all p $<0.05)$. No postoperative urinary incontinence was detected.

Conclusions: The present findings suggest that HoLAP is a slightly time-spending procedure, thus its use should be limited to prostate volume $<70-80 \mathrm{~mL}$. However, no postoperative complications were recorded at all. This technique showed to be a safe option in patients with low-intermediate prostate volume, also in patients whose antiaggregant/ anticoagulant therapy is maintained.

\section{INFORMED CONSENT}

Informed consent was obtained from all individual participants included in the study. All the procedures were in accordance with the ethical standards of the institutional and national research Committee and with the 1964 Helsinki declaration and its later amendments or comparable ethical standards.

\section{CONFLICT OF INTEREST}

None declared. 


\section{REFERENCES}

1. Minervini A, Grosso AA, Di Maida F, Mari A, Vittori G, Muto G, et al. How far is too far? Exploring the indications for robotic partial nephrectomy in a highly complex kidney tumor. Int Braz J Urol. 2020; 46:871-2.

2. Grosso AA, Di Maida F, Tellini R, Mari A, Sforza S, Masieri L, et al. Robot-assisted partial nephrectomy with 3D preoperative surgical planning: video presentation of the florentine experience. Int Braz J Urol. 2021;47:1272-3.

3. Tuccio A, Sessa F, Campi R, Grosso AA, Viola L, Muto G, et al. En-bloc endoscopic enucleation of the prostate: a systematic review of the literature. Minerva Urol Nefrol. 2020; 72:292-312.
4. Tuccio A, Grosso AA, Sessa F, Salvi M, Tellini R, Cocci A, Viola L, Verrienti P, Di Camillo M, Di Maida F, Mari A, Carini M, Minervini A. En-Bloc Holmium Laser Enucleation of the Prostate with Early Apical Release: Are We Ready for a New Paradigm? J Endourol. 2021; 17. ahead of print.

5. Tunc L, Yalcin S, Kaya E, Gazel E, Yılmaz S, Aybal HC, et al. The "Omega Sign": a novel HoLEP technique that improves continence outcomes after enucleation. World J Urol. $2021 ; 39: 135-41$.
Submitted for publication:

June 07, 2021

Accepted after revision:

June 15, 2021

Published as Ahead of Print:

September 10, 2021
Correspondence address: Antonio Andrea Grosso, MD

Department of Experimental and Clinical Medicine, University of Florence, Unit of Oncologic Minimally-Invasive Urology and Andrology,

Careggi Hospital

Largo Brambilla, 3, Florence, 50134, Italy

E-mail: grossoantonioandrea@gmail.com

\section{ARTICLE INFO}

\section{iD Antonio Andrea Grosso}

https://orcid.org/0000-0001-5973-789X

Available at: http://www.intbrazjurol.com.br/video-section/20210455_Grosso_et_al

Int Braz J Urol. 2022; 48 (Video \#3): 200-1 